\title{
Indirect-comparison meta-analysis of treatment options for patients with refractory Kawasaki disease
}

\author{
Han Chan ${ }^{1}$, Huan Chi ${ }^{2}$, Hui You², Mo Wang ${ }^{1}$, Gaofu Zhang ${ }^{1}$, Haiping Yang ${ }^{* *}$ and Qiu Li ${ }^{* *}$ (D)
}

\begin{abstract}
Background: There is limited information available regarding the clinical management of intravenous immunoglobulin-resistant Kawasaki disease (KD). We aimed to evaluate the optimal treatment options for patients with refractory KD by presenting an indirect-comparison meta-analysis.

Methods: PubMed, EMBASE, Web of Science, and the Cochrane Database were searched on August 31, 2018. Unpublished studies were also searched in ProQuest Dissertations \& Theses and through manual retrieval strategies. Randomized concurrent controlled trials (RCTs), high-quality non-randomized concurrent controlled trials (non-RCTs) , and retrospective studies associated with AEs were included. The quality of all eligible studies was assessed using Cochrane collaboration's tool and non-randomized study guidelines. Risk ratios (RR) with 95\% confidence intervals (Cls) for dichotomous outcomes were estimated in our analysis. GRADE profiler 3.6.1 was used to assess the evidence profile.
\end{abstract}

Results: Twelve studies involving 372 immunoglobulin-resistant KD patients were identified and analyzed. Neither infliximab nor intravenous pulse methylprednisolone (IVMP) was significantly more effective than second IVIG infusion with respect to lowering coronary artery lesions (CALs) (infliximab, 0.85, 0.43-1.69; IVMP, 0.99, 0.52-1.88) and treatment resistance (infliximab, 0.43, 0.21-0.89; IVMP, 1.16, 0.33-4.13). No significant differences were found between infliximab and IVMP in the incidence rate of CALs $(0.70,0.27-1.81)$, the treatment resistance $(0.37,0.09-1.60)$, the rates of coronary artery aneurysm $(4.13,0.38-45.22)$ and the coronary artery dilatation $(0.45,0.10-1.99)$. Furthermore, compared with second IVIG infusion, both infliximab and IVMP showed significant effectiveness in antipyretic effects (infliximab, 1.52, 1.16-1.99; IVMP, 1.29, 0.77-2.15). However, Infliximab was noninferior to IVMP on antipyretic effects (1.18, 0.66-2.15). IVMP treatment showed significant association with fewer AEs than second IVIG infusion $(0.49,0.26-0.94)$ and infliximab $(2.34,1.07-5.09)$. No significant differences were noted between infliximab treatment and second IVIG infusion (1.06, 0.69-1.63).

Conclusions: Infliximab, IVMP, and second IVIG infusion showed no significant differences in the cardioprotective effect or the rate of treatment resistance. Infliximab and IVMP treatment were more effective than second IVIG infusion regarding antipyretic effects. IVMP treatment may have an advantage due to its lower total rate of AEs associated with drug infusion.

Trial registration: The study has been registered on PROSPERO (CRD42016039693).

Keywords: Mucocutaneous lymph node syndrome, Immunosuppressant, Intravenous immunoglobulin, Methylprednisolone, Infliximab, Second IVIG infusion

\footnotetext{
*Correspondence: oyhp0708@163.com; liqiu809@126.com

'Department of Nephrology, Children's Hospital of Chongqing Medical

University, Ministry of Education Key Laboratory of Child Development and

Disorders, China International Science and Technology Cooperation base of

Child Development and Critical, Chongqing 400014, China

Full list of author information is available at the end of the article
}

(c) The Author(s). 2019 Open Access This article is distributed under the terms of the Creative Commons Attribution 4.0 International License (http://creativecommons.org/licenses/by/4.0/), which permits unrestricted use, distribution, and reproduction in any medium, provided you give appropriate credit to the original author(s) and the source, provide a link to the Creative Commons license, and indicate if changes were made. The Creative Commons Public Domain Dedication waiver (http://creativecommons.org/publicdomain/zero/1.0/) applies to the data made available in this article, unless otherwise stated. 


\section{Background}

Kawasaki disease (KD) is an acute self-limited systemic vasculitis that occurs mainly in infants and children [1]. KD involves multiple organs and tissues. Approximately fifteen to $25 \%$ of untreated children with KD develop coronary artery lesions (CALs) or coronary artery aneurysms(CAA) [2]. CALs are associated with myocardial infarction, sudden death, and heart disease [3]. Relevant treatment in the acute phase is directed at reducing inflammation in the coronary artery wall and preventing CALs. Intravenous immunoglobulin (IVIG) is recognized as the first-line therapy for $\mathrm{KD}$, and it has been shown to reduce the incidence of CALs. However, at least $10 \%$ of patients with KD fail to respond to initial IVIG treatment $[4,5]$, and second IVIG infusion $(2 \mathrm{~g} / \mathrm{kg})$ has become a common practice. However, fever persists in approximately half of KD patients who receive a second IVIG dose, and this subset of patients has a higher risk than other subsets of developing CALs [6]. Therefore, the identification of additional potentially useful therapies for the treatment of immunoglobulin-resistant KD has become a focus of clinical trials [7].

Intravenous pulse methylprednisolone (IVMP, $30 \mathrm{mg} / \mathrm{kg}$ for 2 to $3 \mathrm{~h}$ once daily for 1 to 3 days) is the most commonly used steroid regimen, which rapidly inhibits inflammation and suppresses cytokine levels in KD patients. Several clinical trials have investigated the efficacy of steroids in IVIG nonresponders [8-12], but some were poor-quality randomized controlled trials (RCTs) or revealed controversial results. Thus far, the role of IVMP in the initial treatment of immunoglobulin-resistant KD patients has not been established. Infliximab is a chimeric monoclonal antibody against TNF- $\alpha$ under investigation in several clinical trials as a treatment for children who fail to respond to initial IVIG [13-15]. Similar to IVMP, infliximab is regarded as a new adjunctive therapy that may have positive effects in the treatment of patients with acute KD [16].

Currently, infliximab, IVMP, and second IVIG infusion are the conventional care for immunoglobulin-resistant KD patients who have failed the initial standard therapy. However, the efficacy of and adverse effects (AEs) associated with these drug administrations are not well known. In the absence of any trials directly assessing the efficacy and AEs of infliximab and methylprednisolone treatment for immunoglobulin-resistant KD, one method to evaluate efficacy and AEs is to conduct an adjusted indirect comparison of data from existing trials with a common control [17].

An indirect comparison is an ideal method by which to resolve issues when there is no direct evidence from current clinical trials. If direct evidence of both $\alpha$ versus $\gamma$ and $\beta$ versus $\gamma$ is available, an indirect comparison of $\alpha$ versus $\beta$ is conducted using the same intervention $\gamma$ as a common comparator. The meta-analysis defined second IVIG infusion as the common comparator. This adjusted indirect comparison meta-analysis aimed to evaluate the safety and effectiveness of these three therapies for children with immunoglobulin-resistant KD in the hope of providing evidence-based clinical advice.

\section{Methods}

Ethical approval was not required because this was a meta-analysis of previously published trials and no real patients were included. The meta-analysis conformed to standard guidelines and was written according to the PRISMA statement [18]. This review also follows a published protocol [19].

\section{Data collection and analysis \\ Database search strategy}

We searched PubMed, EMBASE, Web of Science, and the Cochrane Database for articles published from each database's date of inception to August 31, 2018, using a combination of basic text and $\mathrm{MeSH}$ terms. Specifically, we performed a $\mathrm{MeSH}$ search using 'mucocutaneous lymph node syndrome' and a keyword search using the phrase 'Kawasaki disease' and terms related to intravenous immunoglobulin (including a $\mathrm{MeSH}$ search using 'immunoglobulins, intravenous' and a keyword search using the words 'intravenous immunoglobulin', 'intravenous gamma globulin,' 'IVIG,' 'IVGG', and 'IG'). This search strategy was modified to fit each database. In addition, unpublished studies were searched in ProQuest Dissertations \& Theses and following manual retrieval strategies; we reviewed (1) references from published articles to identify additional relevant studies, (2) conference proceedings likely to contain trials relevant to the analysis, and (3) unpublished data or incomplete trials for relevant trial authors. All searches included non-English language literature (for the full search strategy, see Additional file 1).

\section{Selection criteria and process}

The following studies were included in the meta-analysis: (1) RCTs and high-quality non-randomized concurrent controlled trials (non-RCTs); retrospective studies (e.g., cohort studies or case-control studies) associated with AEs were reviewed; (2) studies whose patient populations included children with immunoglobulin-resistant KD according to the criteria of the Japanese Ministry of Health and Welfare [20] or the American Heart Association (AHA) [1], which defines immunoglobulin-resistant KD as KD characterized by persistent or recrudescent fever lasting longer than the specified observation period (24, 36 , or $36-48 \mathrm{~h}$ ) after completion of an initial IVIG infusion; (3) studies including patients considered to have diseases complicated by CALs (i.e., patients with dilatations 
or aneurysms of varying severity according to the classical criteria of the Japanese Ministry of Health and Welfare or AHA); (4) studies including patients who received infliximab or IVMP treatment for immunoglobulin-resistant KD after failing initial IVIG therapy; (5) treatment resistance was defined as the need for further treatment after completing infliximab or IVMP treatment. Antipyretic effects were defined as fever resolution or a significant decrease in a persistent fever within 3 days of completing the drug infusion without another explanation; and (6) studies with baseline patient demographics, disease characteristics, laboratory data, and CALs incidence that were similar between the two groups. Studies that failed to meet the inclusion criteria were excluded from the analysis.

\section{Data collection and outcome measures}

Studies were selected by 2 independent reviewers $(\mathrm{H}$. You and $\mathrm{H}$. Chi) according to the above inclusion criteria, and disputes regarding the studies were resolved by $\mathrm{H}$. Chan. Data extracted from each study included the publication year, age, setting, design, number of cases, initial course of the disease, initial treatment, retreatment, and the follow-up time points at which echocardiographic assessments were performed. The primary outcomes were CALs and the rate of treatment resistance. The secondary outcomes were AEs associated with drug infusion and antipyretic effects.

\section{Assessment of the risk of bias in included studies}

The methodological quality of the included RCTs was assessed using the Cochrane collaboration tool to assess the risk of bias [21]; The Methodological Index for Non-Randomized Studies (MINORS) guidelines were selected to assess the methodological quality of the non-RCTs [22]. A quality assessment of the studies was performed using the NOS (http://www.ohri.ca/pro grams/clinical_epidemiology/oxford.asp) under the three main categories [23].The overall quality of the evidence and strength of the recommendations were evaluated using the GRADE system [24].

\section{Statistical analysis}

A traditional pair-wise meta-analysis was conducted. All statistical analyses were performed using Stata 14.0 software (Stata Corp., College Station, TX, USA) [25]. The risk of bias assessment was performed with Review Manager 5.3 software (The Nordic Cochrane Centre, Copenhagen, Denmark), in accordance with the guidelines outlined in the Cochrane Handbook (version 5.1.0) [21]. We estimated the Risk ratios (RR) and 95\% confidence interval (CI) for dichotomous outcomes and used a random-effects model regardless of the presence of heterogeneity. Sensitivity analyses were performed to evaluate the effect of each study on the pooled RR.
Between-study heterogeneity was tested using the $I^{2}$ test and considered significant at $I^{2}>50 \%$ or $P<0.1$. GRADE profiler 3.6.1 was used to assess the evidence profile [26].

\section{Results}

\section{Study selection and description}

We initially identified 7128 potentially relevant studies (Fig. 1). A total of 12 studies, being published between 2003 and 2018, were included in the meta-analysis according to the inclusion and exclusion criteria, of which, nine studies were RCTs, while remaining trials were non-RCTs, according to the Cochrane Handbook. Those two non-RCTs trials (Furakawa et al. [9] and Teraguchi et al. [12]) did not adopt random sequence generation because a portion of their patients refused IVMP treatment and were treated with second IVIG infusion instead. Neither the blinding method nor the allocation concealment method was mentioned in the reports of the non-RCTs. In addition, six studies defined the body temperature being over $38^{\circ} \mathrm{C}$ as a symbol of recurrent or persistent fever of non-responsiveness in $\mathrm{KD}$ patients while two other studies each adopted $37.5^{\circ} \mathrm{C}$ and $38.3^{\circ} \mathrm{C}$, and this cut off value was not recorded in two other studies. Six studies defined $36 \mathrm{~h}$ as the observation period after drug infusion, five studies used $36-48 \mathrm{~h}$, and one study used $24 \mathrm{~h}$. Treatment groups had similar baseline characteristics at admission, including sex, ethnicity, age at fever onset, time from fever onset to diagnosis, and time from first treatment to retreatment. Discrepant inflammation intensity between treatment groups was reported in many of the selected studies but not in Youn et al. [15], Tremoulet et al. [16], Son et al. [27], Furakawa et al. [9], Masaaki et al. [28], and Newburger et al. [29].

Overall, the 12 selected studies included 372 patients with immunoglobulin-resistant $\mathrm{KD}$ after removing the ineligible patients in the studies by Tremoulet et al. [16], Sundel et al. [30] and Newburger et al. [29]. The follow-up time point at which echocardiography was performed ranged from study entry to 7 months post-treatment in the infliximab group. In the IVMP treatment group, the follow-up time point ranged from study entry to 6 weeks post-treatment. Table 1 presents the characteristics of included studies.

\section{Risk of bias of included studies}

Two non-RCTs had scores ranging from 19 to 20 points according to the MINORS guidelines (Table 1), and both of these non-RCTs were marked as high quality. In accordance with the Newcastle-Ottawa scale (NOS) scale, the retrospective study scored 8 points and was judged to be of high relative quality (Fig. 2). Compared with the infliximab trials, the IVMP trials were of relatively low quality. Additionally, the risk of bias assessed by the Cochrane collaboration tool was higher in the IVMP 


\section{Potential studies identified 1657 Pubmed 3802 EMbase 1191 Web of science 228 Cochrane Database}

\section{Additional studies identified through other sources 250 Proquest Dissertations \& Theses 0 Manual retrieval}

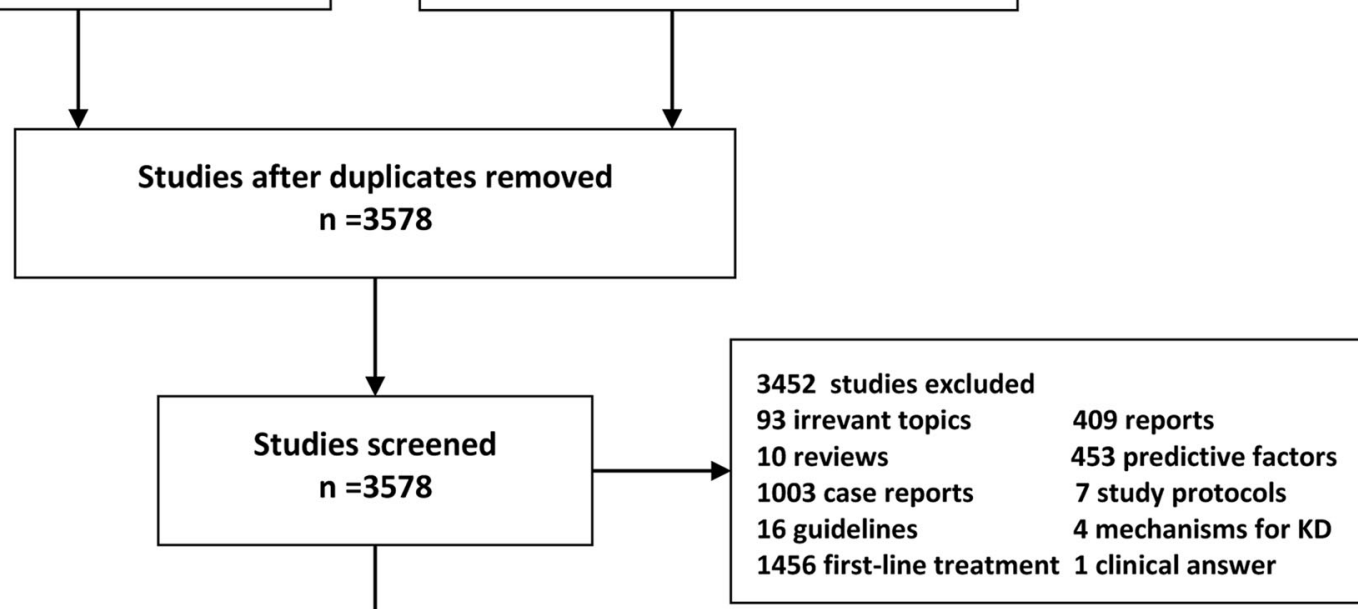

\begin{tabular}{|c|c|}
\hline $\begin{array}{l}\text { Full-text articles assessed } \\
\text { for eligibility } \\
\qquad n=126\end{array}$ & $\begin{array}{l}114 \text { full-text articles excluded } \\
60 \text { retrospective studies without AEs } \\
48 \text { irrelevant medicines/treatments: } \\
16 \text { salicylate } \\
2 \text { ulinastatin } \\
2 \text { clarithromycin } \\
1 \text { cyclosporin A }\end{array}$ \\
\hline & $\begin{array}{l}13 \text { other traditional medicines } \\
11 \text { combination treatments in observational } \\
\text { study }\end{array}$ \\
\hline $\begin{array}{l}\text { Studies included } \\
\qquad(n=12) \\
9 \text { RCTs }\end{array}$ & $\begin{array}{ll}1 & \text { normal control group } \\
3 & \text { no data in the control group } \\
1 & \text { Egami score } \\
1 & \text { non-available for full-text articles }\end{array}$ \\
\hline
\end{tabular}

Fig. 1 Flow diagram for selection of trials and reasons for study exclusion

trials than in the infliximab trials because the IVMP trials discussed only randomization without providing information regarding allocation concealment or blinded measurements, which might indicate a possible source of selection and performance bias (Fig. 2).

\section{Primary outcome}

\section{CALs}

Neither infliximab nor IVMP treatment was significantly more beneficial than second IVIG infusion with respect to reducing the total incidence rate of CALs in patients with immunoglobulin-resistant KD (infliximab, 0.85, $0.43-1.69, \quad P=0.46$; IVMP, $0.99,0.52-1.88, \quad P=0.49$; Fig. 3a). No significant differences in the risk of a coronary artery aneurysm (infliximab, 4.00, 0.52-30.76; IVMP, $0.84,0.29-2.46, P=0.24$; Fig. $3 \mathrm{~b})$ or coronary artery dilatation (infliximab, $0.64,0.22-1.81, P=0.87$; IVMP, 1.39,
0.48-4.00; Fig. 3c) were found between the two treatment groups. No significant heterogeneity was observed among the studies $\left(I^{2}=0 \%\right)$. The indirect comparison relative risk (RR) of the total incidence rate of CALs for infliximab versus IVMP was $0.70(0.27-1.81, P=0.46)$. No significant difference between infliximab and IVMP was found in the rate of coronary artery aneurysm (4.13, $0.38-45.22, P=0.25)$ or coronary artery dilatation $(0.45$, $0.10-1.99, P=0.29$ ).

\section{Treatment resistance}

The rate of treatment resistance was not higher in the infliximab group than in the second IVIG infusion group (0.43, $0.21-0.89, \quad P=0.68$, Fig. 4). Similarly, the meta-analysis showed that IVMP did not provide significantly more benefit than second IVIG infusion with respect to the rate of treatment resistance $(1.16,0.33-4.13$, 
Table 1 Characteristics of the trials included in the analysis

\begin{tabular}{|c|c|c|c|c|c|c|c|c|c|c|}
\hline Author & Year & $\begin{array}{l}\text { Patient age } \\
\text { (treatment/ } \\
\text { control) }\end{array}$ & Setting & Design & Cases & $\begin{array}{l}\text { Disease } \\
\text { course }\end{array}$ & $\begin{array}{l}\text { Initial } \\
\text { treatment }{ }^{\mathrm{a}} \\
\text { (treatment/ } \\
\text { control) }\end{array}$ & $\begin{array}{l}\text { Retreatment } \\
\text { (treatment/ } \\
\text { control) }\end{array}$ & Follow-up & $\begin{array}{l}\text { NOS } \\
\text { /MINORS }\end{array}$ \\
\hline Burns et al. [14] & 2008 & 22/20 months & US & RCT & $12 / 12$ & 2-7 days & IVIG 2 & $\begin{array}{l}\text { Infliximab } \\
5 / \mathrm{IVIG} 2\end{array}$ & $\begin{array}{l}\text { Study entry } \\
1-2 \text { weeks } \\
6-8 \text { weeks } \\
<7 \text { months }\end{array}$ & - \\
\hline Youn et al. [15] & 2016 & $\begin{array}{l}3 \text { months- } \\
13 \text { years }\end{array}$ & Korea & RCT & $11 / 32$ & 3-8 days & IVIG 2 & $\begin{array}{l}\text { Infliximab } \\
5 / \mathrm{IVIG} 2\end{array}$ & $\begin{array}{l}\text { Study entry } \\
2-4 \text { weeks }\end{array}$ & - \\
\hline $\begin{array}{l}\text { Tremoulet et al. } \\
\text { [16] }\end{array}$ & 2014 & $3.0 / 2.8$ years & US & RCT & $98 / 98$ & $\begin{array}{l}3-10 \\
\text { days }\end{array}$ & $\begin{array}{l}\text { IVIG } 2+ \\
\text { Infliximab } 5 \\
\text { IVIG } 2+\text { Normal } \\
\text { saline }\end{array}$ & IVIG 2 & $\begin{array}{l}\text { Study entry } \\
2-5 \text { weeks }\end{array}$ & - \\
\hline Son et al. [27] & 2011 & 23/29 months & US & Retrospective & 20/86 & 4-7 days & IVIG 2 & $\begin{array}{l}\text { Infliximab } \\
5 / \mathrm{IVIG} 2\end{array}$ & $\begin{array}{l}\text { Study entry } \\
1-10 \text { weeks }\end{array}$ & 8 \\
\hline $\begin{array}{l}\text { Masaaki et al. } \\
\text { [28] }\end{array}$ & 2018 & $2.5 / 3.0$ years & Japan & RCT & $16 / 15$ & 6-7 days & IVIG 2 & Infliximab 5 & $\begin{array}{l}\text { Study entry } \\
8 \text { week }\end{array}$ & - \\
\hline Miura et al. [8] & 2005 & N/A & Japan & $\mathrm{RCT}$ & $11 / 11$ & N/A & IVIG 2 & $\begin{array}{l}\text { IVMP } 30 \text { for } 3 \\
\text { consecutive } \\
\text { days/IVIG } 2\end{array}$ & $\begin{array}{l}\text { Study entry } \\
1 \text { week }\end{array}$ & - \\
\hline $\begin{array}{l}\text { Furakawa et al. } \\
\text { [9] }\end{array}$ & 2007 & $\begin{array}{l}31.3 / 28.1 \\
\text { months }\end{array}$ & Japan & Non-RCT & $44 / 19$ & N/A & IVIG 2 & $\begin{array}{l}\text { IVMP } 30 \text { for } 3 \\
\text { consecutive } \\
\text { days/IVIG } 2\end{array}$ & 4 weeks & 19 \\
\hline Miura et al. [10] & 2008 & $\begin{array}{l}32 \pm 19 / 32 \pm 26 \\
\text { months }\end{array}$ & Japan & RCT & $7 / 8$ & 4-5 days & IVIG 2 & $\begin{array}{l}\text { IVMP } 30 \text { for } 3 \\
\text { consecutive } \\
\text { days/IVIG } 2\end{array}$ & $\begin{array}{l}\text { Study entry } \\
1 \text { week }\end{array}$ & - \\
\hline Ogata et al. [11] & 2009 & $\begin{array}{l}14 \pm 17 / 33 \pm 24 \\
\text { months }\end{array}$ & Japan & $\mathrm{RCT}$ & $13 / 14$ & 4-5 days & IVIG 2 & $\begin{array}{l}\text { IVMP } 30 \text { for } 3 \\
\text { consecutive } \\
\text { days/IVIG } 2\end{array}$ & $\begin{array}{l}\text { Before } \\
\text { discharge }\end{array}$ & - \\
\hline $\begin{array}{l}\text { Teraguchi et al. } \\
\text { [12] }\end{array}$ & 2013 & $1-120$ months & Japan & Non-RCT & $14 / 27$ & N/A & IVIG 2 & $\begin{array}{l}\text { IVMP } 30 \text { for } 3 \\
\text { consecutive days }\end{array}$ & 4 weeks & 20 \\
\hline $\begin{array}{l}\text { Sundel et al. } \\
\text { [30] }\end{array}$ & 2003 & $4.3 / 4.5$ years & US & RCT & $18 / 21$ & $\begin{array}{l}6.5 / 6.9 \\
\text { days }\end{array}$ & $\begin{array}{l}\text { IVIG } 2+\text { IVMP } \\
30 / I V I G ~\end{array}$ & N/A & 2 and 6 weeks & - \\
\hline $\begin{array}{l}\text { Newburger et al. } \\
\text { [29] }\end{array}$ & 2007 & $2.9 / 2.9$ years & US & RCT & $\begin{array}{l}101 / \\
97\end{array}$ & $\begin{array}{l}4-10 \\
\text { days }\end{array}$ & $\begin{array}{l}\text { IVIG } 2+\text { IVMP } \\
30 / I V I G 2\end{array}$ & IVIG 2 & $\begin{array}{l}\text { Study entry } \\
1 \text { and } 5 \text { weeks }\end{array}$ & - \\
\hline
\end{tabular}

${ }^{\mathrm{a}} \mathrm{VIG} \mathrm{g} \mathrm{kg}^{-1}$ day $^{-1}$, IVMP $\mathrm{mg} \mathrm{kg}^{-1}$ day $^{-1}$, Infliximab $\mathrm{mg} \mathrm{kg}^{-1}$ day $^{-1}$, N/A Not available

$P=0.03$, Fig. 4). The indirect comparison $R R$ of the rate of treatment resistance for infliximab versus IVMP was 0.37 (0.09-1.60, $P=0.18)$. Therefore, no significant difference in treatment resistance was found between infliximab and IVMP.

\section{Secondary outcomes \\ Antipyretic effects}

Infliximab was associated with significant antipyretic effects than second IVIG infusion (1.52, 1.16-1.99, $P=$ 0.78, Fig. 5a). However, no significant differences were recorded between the IVMP group and the IVIG retreatment group $(1.29,0.77-2.15, P=0.02$, Fig. 5a) concerning the high level of heterogeneity $\left(I^{2}=69.0 \%\right)$. The indirect comparison RR of antipyretic effects for infliximab versus IVMP was $1.18(0.66-2.15, P=0.58)$, indicating that the antipyretic effects of infliximab and IVMP were not significantly different.

\section{AEs}

Ten studies reported all AEs during the disease course $[8,10,12,14-16,27-30]$. In addition, eight of the studies reported AEs associated with infliximab or IVMP (Fig. 8). In summary, more AEs were reported in the IVMP group (Table 2), particularly bradycardia (3.98, 1.62-9.77, $P=0.76$, Fig. 6), hyperglycemia (12.70, 1.81$88.88, P=0.98$, Fig. 6), and hypertension (1.62, 1.05-2.50, $P=0.77$, Fig. 6). Conversely, patients undergoing infliximab treatment were more likely to suffer from transient hepatomegaly $(8.14,2.01-32.93, P=0.50$, Fig. 7$)$.

Compared to second IVIG infusion, IVMP treatment was associated with fewer AEs $(0.49,0.26-0.94, P=0.50$, Fig. 8). Nevertheless, no significant differences were noted between infliximab treatment and second IVIG infusion (1.06, 0.69-1.63, $P=0.91$, Fig. 8). Additionally, no significant heterogeneity was observed among the studies $\left(I^{2}=0 \%\right)$. The indirect comparison $\mathrm{RR}$ of the total rate of AEs for infliximab versus IVMP was 2.34(1.07- 

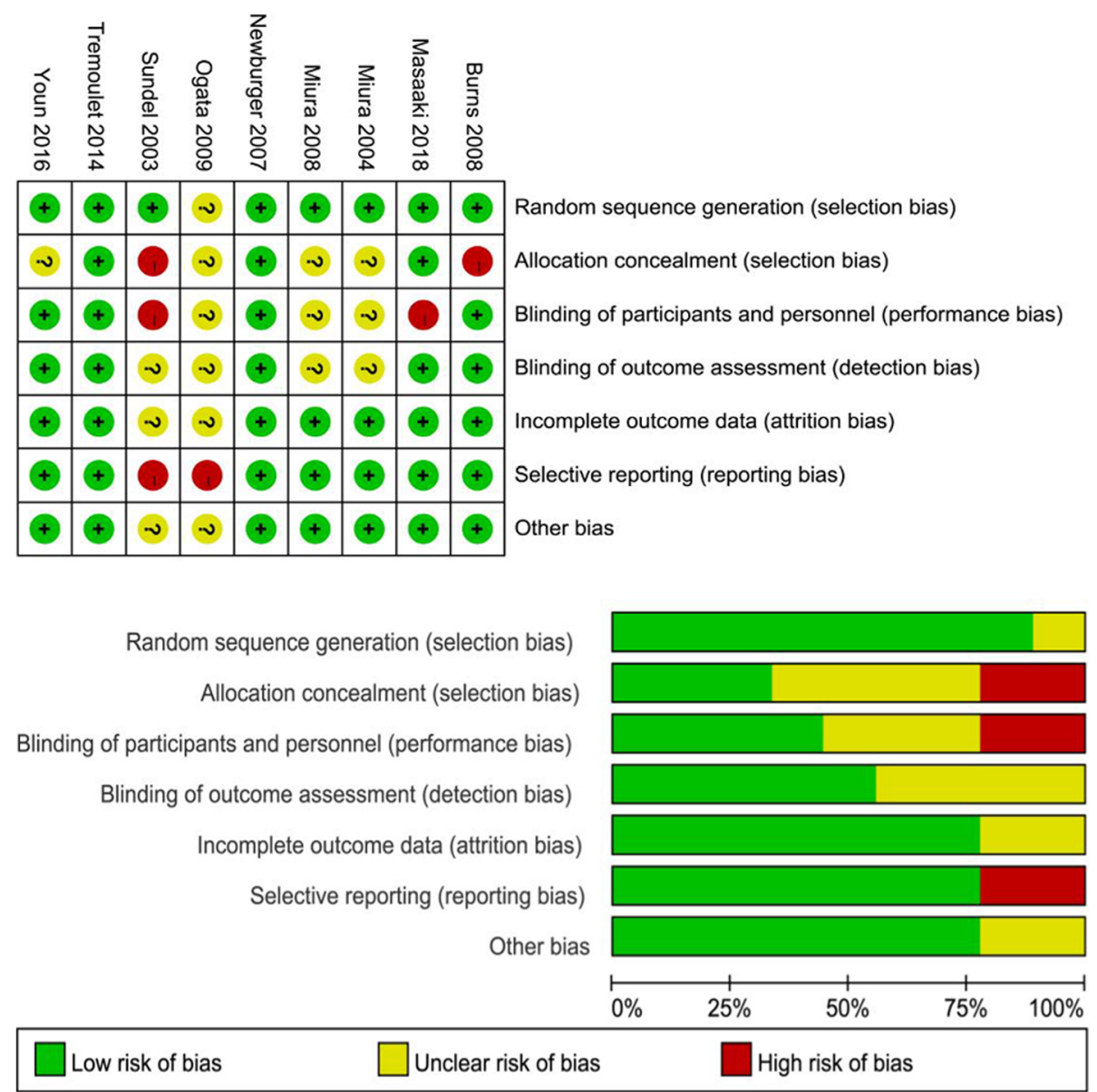

Fig. 2 Assessment of the risk of bias

5.09, $P=0.03)$. The result showed that the total rate of AEs associated with drug infusion was lower for IVMP treatment than for infliximab treatment.

\section{Sensitivity analysis and GRADE evidence profile}

Significant heterogeneity was observed among the included studies in terms of antipyretic effects $\left(I^{2}=69 \%\right)$ and the rate of treatment resistance $\left(I^{2}=78 \%\right)$ in the IVMP treatment group. As shown in Figs. 5a and 9, the data reported in the study conducted by Teraguchi et al. [12] were completely out of range of those reported in other studies and probably contributed to the heterogeneity. The heterogeneity vanished after excluding this study (Fig. 5b). No evidence of heterogeneity was detected among the remaining studies.

Strengthened by the GRADE system, the working group grades of evidence were high for CALs in the infliximab group, moderate for CALs in the IVMP group, high for the rate of treatment resistance in the infliximab group, moderate for the rate of treatment resistance in the IVMP group, moderate for antipyretic action in both groups, moderate for the total rate of AEs associated with drug infusion in the infliximab group, and low for the total rate of AEs associated with drug infusion in the IVMP group. The indirect comparison suggested evidence grades of moderate for CALs between infliximab versus IVMP, low for treatment resistance between infliximab versus IVMP, moderate for antipyretic action between infliximab versus IVMP, and low for AEs associated with drug infusion among infliximab, IVMP, and second IVIG infusion [26].

\section{Publication bias}

Tests for funnel plot asymmetry and meta-regression analyses weren't conducted in the meta-analysis since the number of included studies in pair-wise meta-analysis was $<10$, according to Cochrane Handbook [21].

\section{Discussion}

TNF- $\alpha$ is elevated in the acute phase of KD and may be a contributing factor in patients who subsequently develop a coronary artery aneurysm. Infliximab, which is a chimeric monoclonal antibody against TNF- $\alpha$, has been used to treat patients with immunoglobulin-resistant KD 


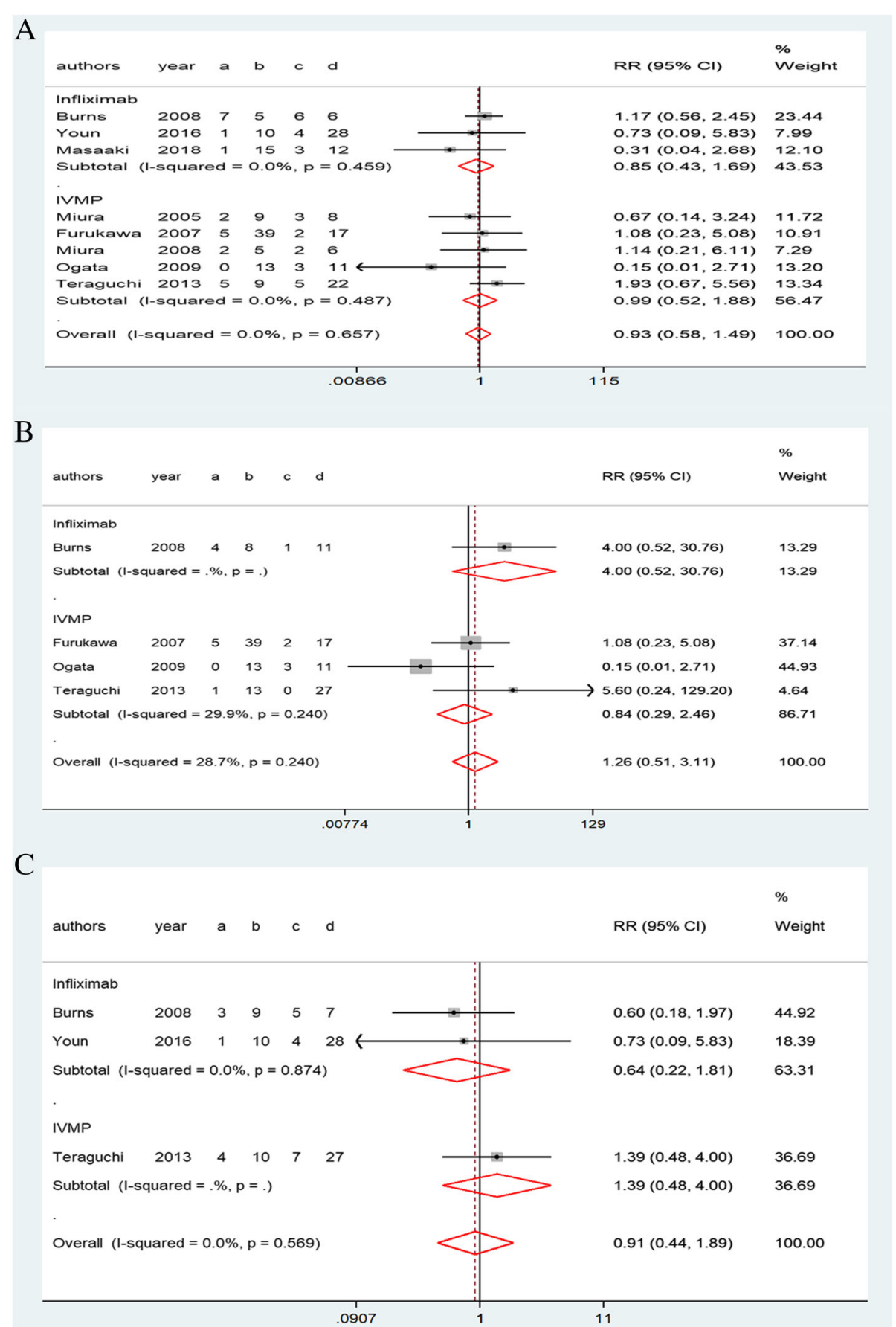

Fig. 3 Forest plots of a traditional pair-wise meta-analysis of CALs in patients with immunoglobulin-resistant KD: (a) total incidence rate of CALs, (b) incidence of coronary artery aneurysms, and (c) incidence of coronary artery dilatation

for the past 10 years. Several studies have suggested that treatment with infliximab results in faster fever resolution, shorter hospitalization, and even improved coronary artery outcomes compared to second IVIG infusion $[15,27]$ and that further treatment with infliximab may be an effective option for immunoglobulin/glucocorticoid-resistant KD patients with encephalitis [31].
However, the lack of sufficient clinical trials regarding this topic, as well as the small number of subjects included in the available trials, may have led to bias. A meta-analysis in 2017 [32] that included only 4 studies (2 RCTs of immunoglobulin-resistant KD patients, 1 RCT of initial treatment for KD patients, and 1 case-control study) showed that with the exception of 


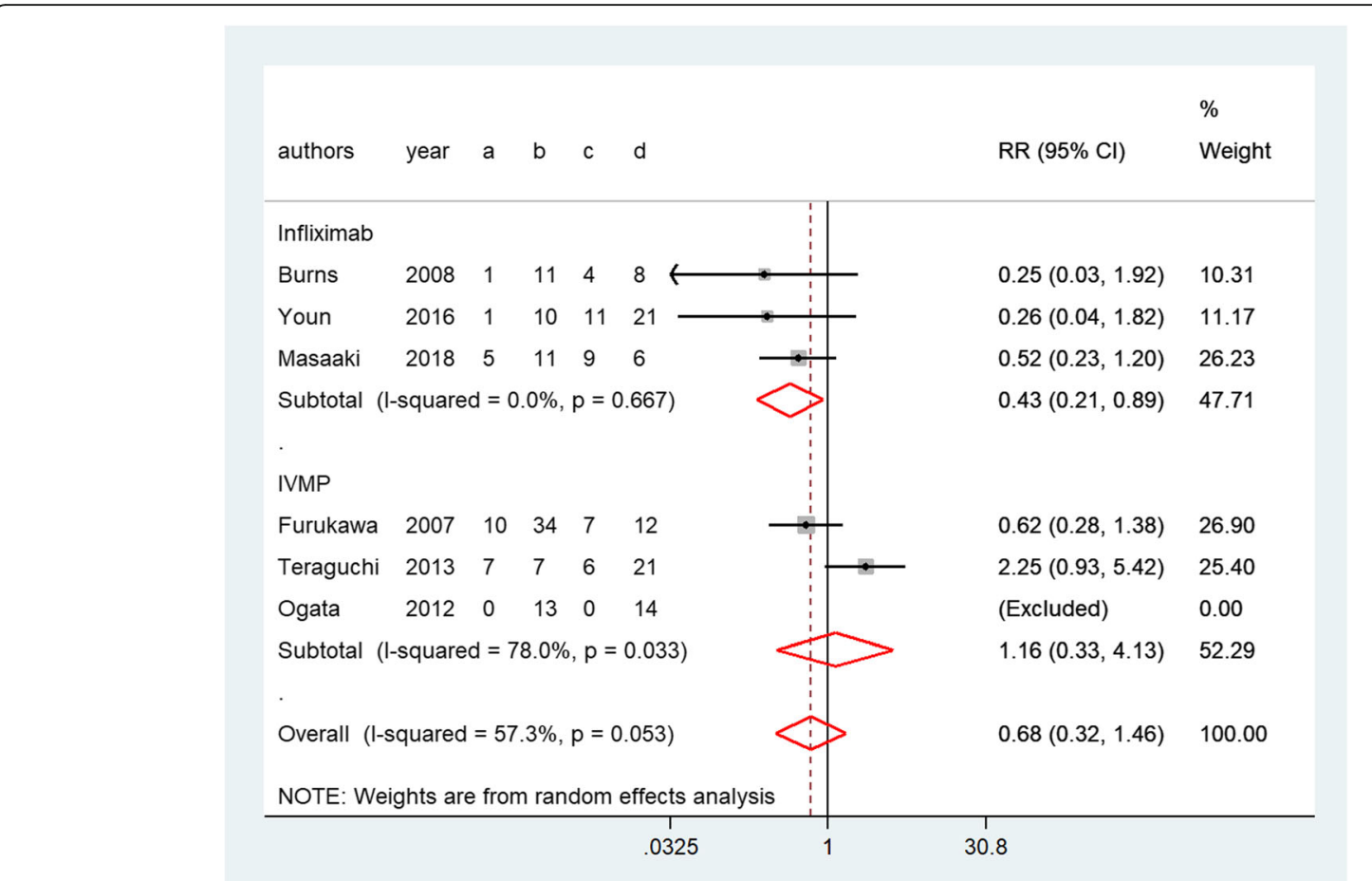

Fig. 4 Forest plots of a traditional pair-wise meta-analysis of the rate of treatment resistance in patients with immunoglobulin-resistant KD

antipyretic action, infliximab did not provide significantly more benefit than second IVIG with respect to the cardioprotective effect, rate of treatment resistance, and total rate of AEs. The authors took full advantage of the limited literature in this meta-analysis and merged data from studies with different designs. Our meta-analysis adopted a strict published protocol [19]. To acquire a reliable conclusion on the drug management of immunoglobulin-resistant KD patients, our meta-analysis not only analyzed infliximab treatment but also focused on an indirect comparison with IVMP treatment. All the outcomes except for AEs were measured predominantly using data from RCTs.

A previous traditional pair-wise meta-analysis of IVMP was published by Yang et al. in 2015 [33]. This analysis included only 4 studies involving a total of 52 patients and showed that IVMP was more effective than second IVIG infusion in controlling body temperature. Specifically, our subgroup analysis showed that IVMP was a more effective antipyretic than second IVIG infusion and that there was no significant difference in the overall incidence of CALs between IVMP and second IVIG. However, we regarded 2nd-line treatments merely as our endpoint; therefore, other drugs (3rd-line treatments) did not affect the realistic incidence of CALs and enabled us to avoid potential reporting bias. Furthermore, the fixed-effects model was not appropriate for the complex moderators in Yang's work [34, 35]. Our meta-analysis further adopted the
GRADE system and included an additional 8 studies (245 additional patients) to acquire more reliable clinical outcomes.

Our meta-analysis suggested that IVMP and infliximab may have limited ability to prevent or treat CALs in immunoglobulin-resistant KD patients, as they showed the same cardioprotective effects as second IVIG infusion. Neither initial IVIG nonresponders nor patients treated with early initial IVIG with methylprednisolone pulse therapy are at a lower risk for coronary artery abnormalities [29]. A retrospective cohort study reported no difference in the prevalence of CALs between spontaneous defervescence KD patients without drug infusion and typical KD patients treated with initial IVIG [36]. Moreover, KD may continue to be associated with the development of severe aneurysms in a small percentage of patients (10\%) who respond to initial IVIG treatment, and half of the children who developed a coronary artery aneurysm did so despite treatment $[37,38]$.

The results revealed that transient hepatomegaly was most likely associated with infliximab treatment $[14,16]$. However, no hepatomegaly events occurred during a larger infliximab trial. The IVMP group reported more AEs during treatment; these events included chills, headache, hemolytic anemia, coagulopathy, hypertension, hypothermia, bradycardia, hyperglycemia, gastrointestinal bleeding, nerve palsy, and shock (Table 2). Nagakura et al. suggested that bradycardia might occur frequently during corticosteroid 


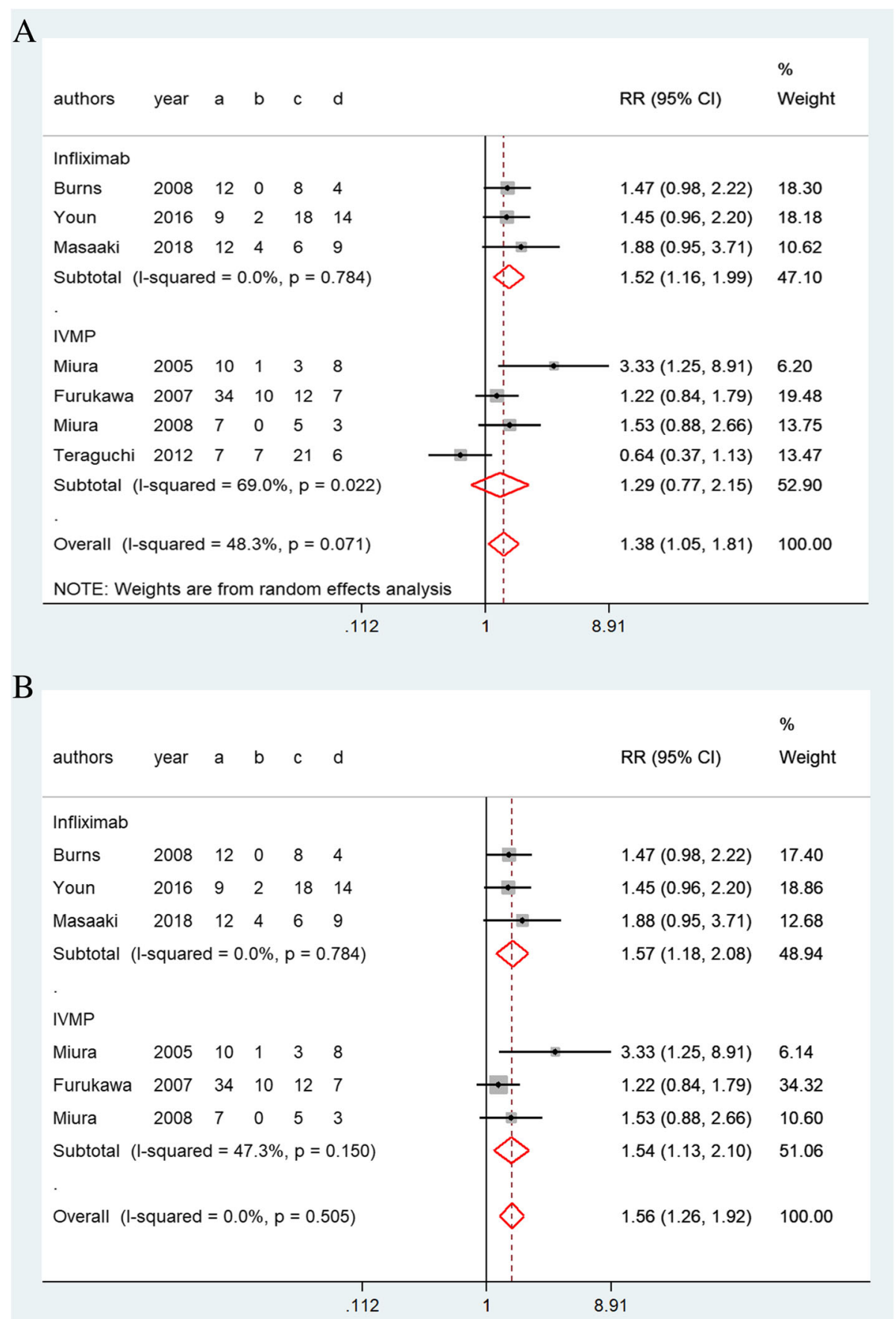

Fig. 5 Forest plots of a traditional pair-wise meta-analysis of the antipyretic effects in patients with immunoglobulin-resistant KD: (a) before and (b) after sensitivity analysis

treatment, and bradycardia was associated with responsiveness to treatment in a cohort study [39]. However, the rate of AEs associated with IVMP infusion was significantly lower than that associated with infliximab or IVIG retreatment, which might be explained by the following two reasons. First, reporting bias may exist for methylprednisolone, as a classic anti-inflammatory drug administered to
IVIG-resistant KD patients, AEs associated with methylprednisolone have been extensively reported. In contrast, infliximab is a chimeric monoclonal antibody that has been used in recent years, and there are relatively few reports of untoward effects. Therefore, the IVMP group reported more AEs than the infliximab group in our meta-analysis. Second, a portion of the reported 
Table 2 The incidence of AEs in the included studies

\begin{tabular}{|c|c|c|c|c|c|c|c|c|c|c|}
\hline \multirow[b]{2}{*}{ Variable } & \multicolumn{4}{|c|}{ Infliximab group (\%) } & \multirow[b]{2}{*}{ Masaaki } & \multicolumn{5}{|c|}{ IVMP group (\%) } \\
\hline & Burns & Youn & Tremoulet & Son & & Miura05 & Miura08 & Teraguchi & Sundel & Newburger \\
\hline Transient hepatomegaly & 41.7 & - & - & 19 & & - & - & - & - & - \\
\hline Chills & - & 0 & - & - & & - & - & - & 6 & - \\
\hline Rash & - & 10 & 1 & - & 12.5 & - & - & - & - & - \\
\hline Headache & - & - & 2 & - & & - & - & - & - & 5 \\
\hline Hemolytic anemia & - & - & 2 & - & & - & - & - & - & 1 \\
\hline Seizure & - & - & 0 & - & & - & - & - & - & - \\
\hline Hepatitis & - & - & 0 & - & & - & - & - & - & - \\
\hline Hypertension & - & - & 0 & - & & 90 & 86 & - & 6 & - \\
\hline Coagulopathy & - & - & 0 & - & & 27 & - & - & - & - \\
\hline Bradycardia & - & - & - & - & & 82 & 86 & - & - & - \\
\hline Hypothermia & - & - & - & - & & 1 & 14 & - & - & - \\
\hline Hypotension & - & - & - & - & & - & - & - & - & 5 \\
\hline Hyperglycemia & - & - & - & - & & 55 & 71 & - & - & - \\
\hline Embolism & - & - & - & - & & 0 & 0 & - & - & - \\
\hline Stool blood & - & - & - & - & & 0 & 0 & 7 & - & - \\
\hline Vomiting & - & - & - & - & 6.3 & - & - & - & 0 & - \\
\hline Heart failure & - & - & - & - & & - & - & - & 0 & 0 \\
\hline Shock & - & - & - & - & & - & - & - & - & 1 \\
\hline
\end{tabular}

AEs were related to immunoglobulin-resistant KD or occurred before drug administration; therefore, they may not reflect the actual difference between the IVMP and infliximab groups.

Millar et al. suggested that corticosteroid use in the acute phase of KD in patients with evolving coronary artery aneurysms might be associated with worsened aneurysms and impaired vascular remodeling [40]. According to the AHA, steroid treatment should be restricted to children in whom $\geq 2$ IVIG infusions have been ineffective for the treatment of persistent fever [1]. To date, several trials have adopted a predicted CAL scoring system and have suggested that steroids may be beneficial in reducing coronary artery aneurysms and safe for patients with immunoglobulin-resistant KD [41, 42]. However, Song et al. revealed that 4 current scoring systems (e.g., Egami, Kobayashi, San Diego, and Formosa) had limited utility in predicting immunoglobulin-resistant KD [43], which indicated that the above trials might have exaggerated the effect of steroid treatment. Conversely, a 2013 meta-analysis showed that IVIG plus corticosteroid therapy as an initial therapy significantly reduced the risk of CALs [44]. Moreover, a recently published meta-analysis highlighted the importance of timing for the prevention of CALs when treating KD patients [45]. Briefly, according to the GRADE evidence profile, although IVMP was not more advantageous than infliximab or second IVIG with respect to cardioprotective effects or lowering the rate of treatment resistance, this treatment might have the ability to attenuate the severity of KD.

Certain laboratory parameters in KD patients are considered useful markers of inflammation that may reflect disease severity and treatment effects; such parameters include leukocyte and platelet counts, erythrocyte sedimentation rate, and the levels of hemoglobin, C-reactive protein, albumin, TNF- $\alpha$, monocyte chemoattractant protein-1 (MCP-1), aspartate aminotransferase (AST) and alanine aminotransferase (ALT). Previous studies revealed that IVIG nonresponders have a higher neutrophil differential, higher C-reactive protein levels, and lower cholesterol levels than responders, and there was a high risk of CALs in patients with more severe and persistent inflammation [46, 47]. Additionally, the available data from the selected studies indicate that the anti-inflammatory effects of IVMP might be superior to those of infliximab. The variations in laboratory findings of IVIG-resistant KD patients may be beneficial for modifying treatment strategies in the future. However, due to a limited number of appropriate studies and the absence of suitable data at presentation, neither inflammatory markers nor laboratory results were analyzed in our meta-analysis. Therefore, a randomized, double-blind, multicenter, parallel-group trial should be conducted to assess IVMP versus infliximab in immunoglobulin-resistant KD patients; this study should contain a standard operation procedure (SOP) for echocardiography based on the AHA guidelines and a stratified 


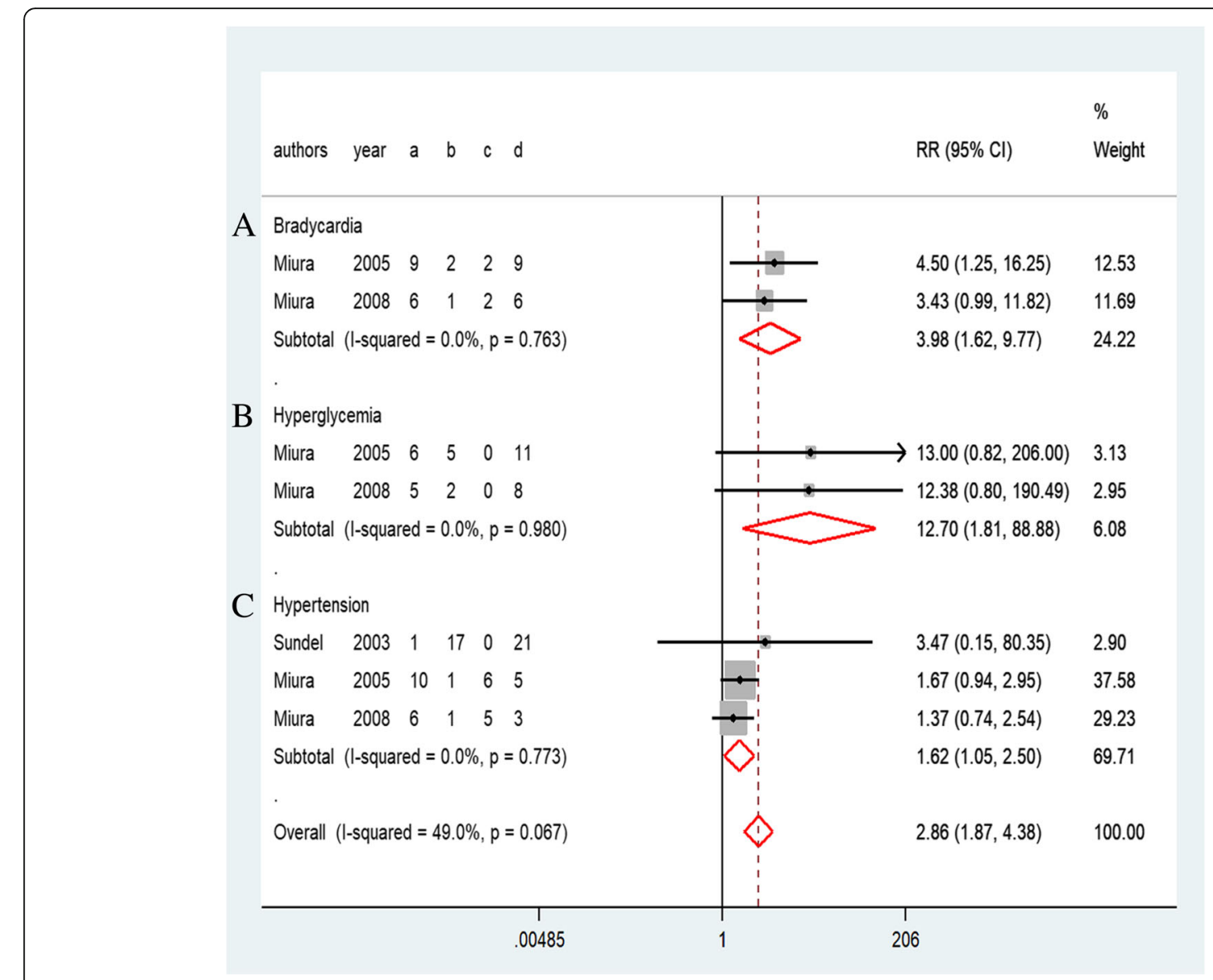

Fig. 6 Forest plots of a traditional pair-wise meta-analysis of variable AEs during IVMP treatment: (a) bradycardia, (b) hyperglycemia, and (c) hypertension

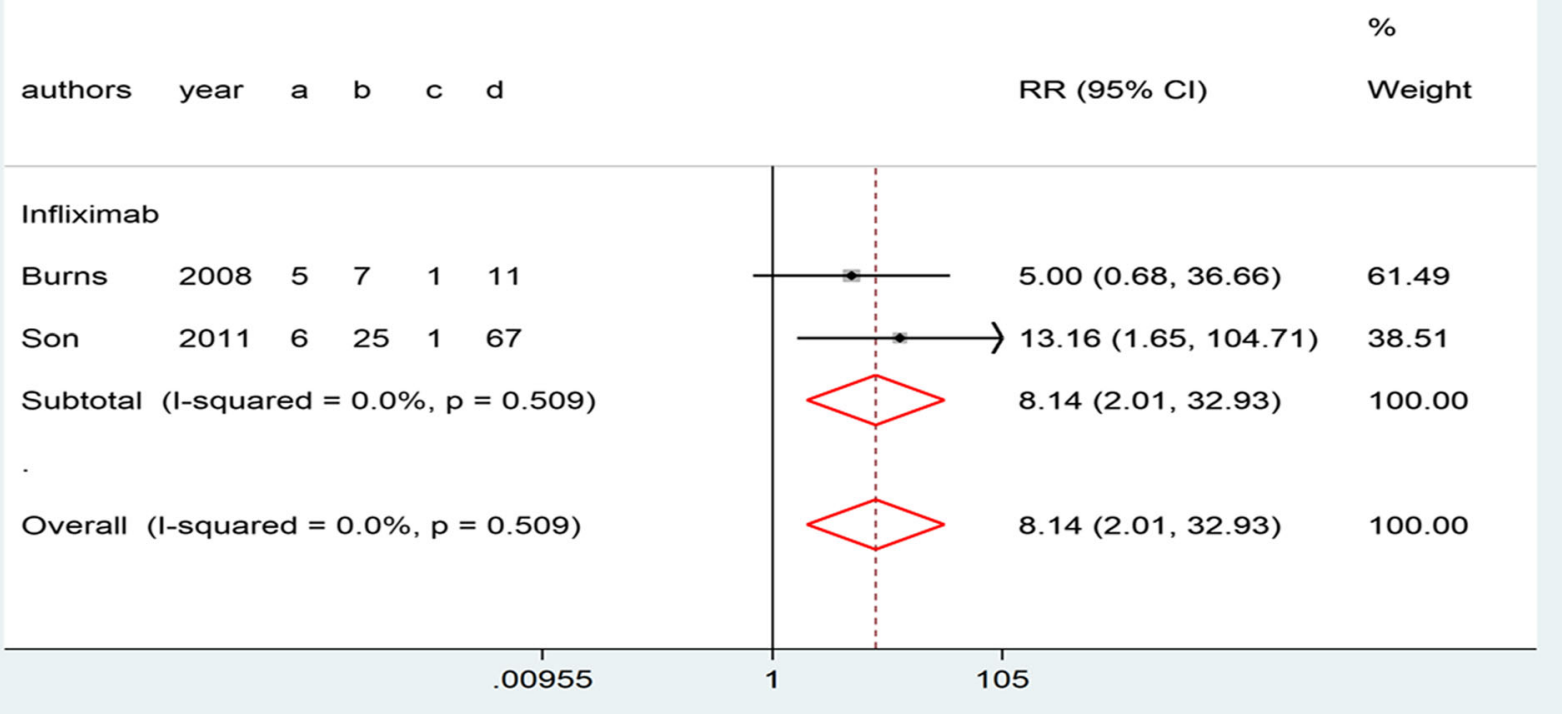

Fig. 7 Forest plots of a traditional pair-wise meta-analysis of transient hepatomegaly during infliximab treatment 


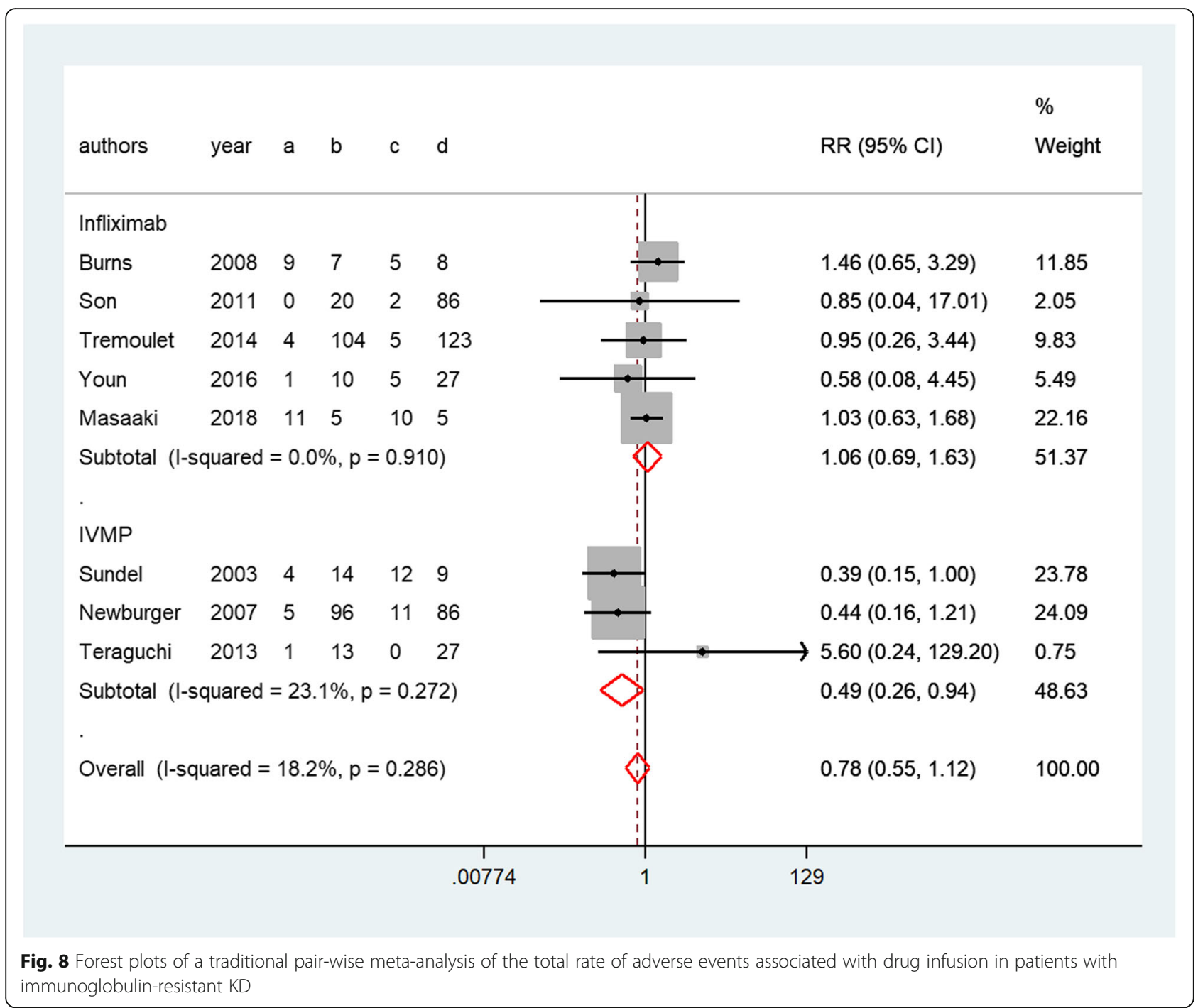

analysis of the initial discrepant inflammation intensity between treatment groups at study entry.

Cardiovascular manifestations and complications are closely connected to morbidity and mortality associated with severe KD, during both acute illness and long-term follow-up. Early diagnosis and early IVIG infusion in incomplete KD patients could reduce the risk of CALs [48, 49]. Risk stratification allows for individualized long-term patient management regarding the frequency of follow-up and diagnostic testing, cardiovascular risk factor assessment and management, medical therapy, thrombo prophylaxis, physical activity, and reproductive counseling, which may have a considerable benefit for severe KD patients [2].

To date, because few clinical trials have assessed the efficacy of medications other than second IVIG treatment, neither the AHA nor the Research Committee of the Japanese Society of Pediatric Cardiology (RCJSPC) reached consensus on the treatment options for IVIG-resistant $\mathrm{KD}$. Both the
AHA and RCJSPC recommend mostly a second IVIG treatment as the best reasonable therapy in IVIG-resistant patients (AHA IIa/B; RCJSPC III/B), secondly as IVMP (AHA $\mathrm{IIb} / \mathrm{B}$; RCJSPC IIb/B), then as infliximab treatment (AHA IIb/C; RCJSPC IIb/C) [1, 26, 50]. Compared to RCJSPC, the AHA (2017) highlighted that IVMP could be considered an effective alternative to a second infusion of IVIG. Meanwhile, our meta-analysis has provided the best available evidence that infliximab, IVMP, and a second IVIG infusion showed no significant differences in the cardioprotective effect or the rate of treatment resistance, but that IVMP has advantages in antipyretic effects and a lower total rate of AEs. For this reason, our study further confirmed the potential value of IVMP treatment in IVIG-resistant KD patients. The results could be conducive for recommending an objective order of these treatment options in later studies and guidelines. In particular, considering the risk-benefit balance of IVIG [50], IVMP could exert more influence on the management of refractory KD patients in the future. 


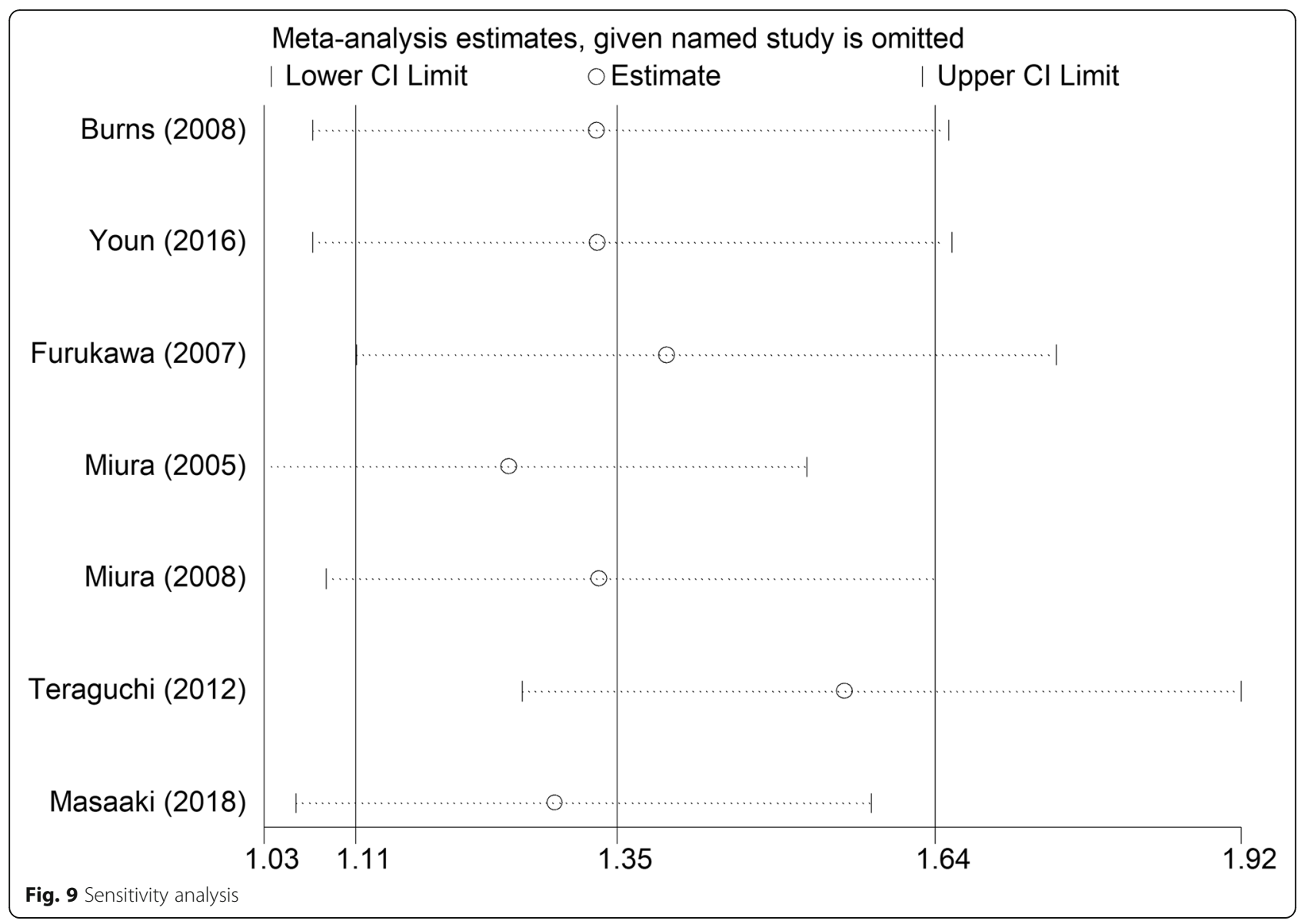

Nevertheless, this meta-analysis had several limitations. First, the use of an indirect comparison might have created differences in the clinical outcomes assessed herein. However, in the absence of sufficient head-to-head data pertaining to different treatments, an adjusted indirect comparison of the treatments in question can produce reasonable results. Some clinicians have even argued that adjusted indirect comparisons produce less bias than direct comparisons [18, 51]. Until data from direct clinical trials are available, the results of our meta-analysis represent the best available evidence. Second, similar to previous pair-wise meta-analyses, there were no detailed definitions of IVIG resistance during the observation period after drug infusion, and the body temperature for non-responsiveness was not uniformly defined in the studies included in our meta-analysis according to the guidelines of the Japanese Ministry of Health and Welfare or the AHA. The differentiation of the observation period may be attributed to the differences between medical systems and ethnicity. Furthermore, differences in the location of body temperature measurements (oral, rectal, and axillary) may have affected the analysis. Heterogeneity among the included studies in the observation period after IVMP or infliximab treatment and the body temperature indicative of IVIG resistance may have introduced potential bias. Third, potential bias may exist because of the initial discrepant inflammation intensity between treatment groups in some of the included studies. Fourth, outcomes associated with a $\mathrm{Z}$ score in an adjusted indirect meta-analysis are needed to better evaluate coronary artery status. Fifth, the reporting bias was minimized, as we retrieved unpublished data from gray literature. However, all the studies included in this analysis were derived from published literature, and some unpublished studies remain missing. Finally, although no significant statistical or clinical heterogeneity was observed across the included studies, potential bias still exists because the relevant literature is limited, and most of the included studies did not completely evaluate the post-retreatment incidence of coronary artery aneurysms in patients with immunoglobulin-resistant KD after a short-term follow-up. Therefore, large homogeneous and randomized clinical trials with long follow-up periods are needed, especially trials involving infliximab. 


\section{Conclusion}

Neither infliximab nor IVMP was associated with cardioprotective effects or decreases in the rate of treatment resistance compared with second IVIG infusion, and both treatments were more effective than second IVIG infusion due to their antipyretic effects. Additionally, IVMP may have an advantage due to its lower total rate of AEs associated with drug infusion. However, the results of this meta-analysis should be interpreted with caution due to the presence of potential limitations. Until data from direct clinical trials comparing infliximab with IVMP are available, our meta-analysis provides preliminary evidence for the optimal management of immunoglobulin-resistant KD patients.

\section{Additional file}

Additional file 1: Search strategy. (DOCX $16 \mathrm{~kb}$ )

\section{Abbreviations}

AEs: Adverse effects; CALs: Coronary artery lesions; IVIG: Intravenous immunoglobulin; IVMP: Intravenous pulse methylprednisolone; KD: Kawasaki disease; Non-RCTs: Non-randomized clinical trials; R: Risk ratio; RCTs: Randomized clinical trials

\section{Acknowledgments}

We are grateful to Dr. Daoqi Wu for his guidance and assistance in the data collection process

\section{Funding}

None.

\section{Availability of data and materials}

All data generated or analysed during this study are included in this published article and its supplementary information files.

\section{Authors' contributions \\ QL proposed and conducted the study, and HY1 and HC2 were responsible for data collection and data extraction. HY2, GZ and MW were responsible for data analysis. $\mathrm{HC} 1$ oversaw the entire study. All read and approved the final manuscript.}

\section{Ethics approval and consent to participate}

Not applicable.

\section{Consent for publication}

Not applicable.

\section{Competing interests}

The authors declare that they have no competing interests.

\section{Publisher's Note}

Springer Nature remains neutral with regard to jurisdictional claims in published maps and institutional affiliations.

\section{Author details}

'Department of Nephrology, Children's Hospital of Chongqing Medical University, Ministry of Education Key Laboratory of Child Development and Disorders, China International Science and Technology Cooperation base of Child Development and Critical, Chongqing 400014, China. ${ }^{2}$ Graduate School of Chongqing Medical University, Chongqing 400016, China.
Received: 2 October 2018 Accepted: 10 April 2019

Published online: 17 May 2019

\section{References}

1. McCrindle BW, Rowley AH, Newburger JW, Burns JC, Bolger AF, Gewitz M, Baker AL, Jackson MA, Takahashi M, Shah PB, Kobayashi T, Wu MH, Saji Tा, Pahl E. American Heart Association rheumatic fever, endocarditis, and Kawasaki disease Committee of the Council on cardiovascular disease in the young; council on cardiovascular and stroke nursing; council on cardiovascular surgery and anesthesia; and council on epidemiology and prevention. Diagnosis, treatment, and long-term Management of Kawasak Disease: a scientific statement for health professionals from the American Heart Association. Circulation. 2017;135(17):e927-99. https://doi.org/10.1161/ CIR.0000000000000484

2. Kato H, Sugimura T, Akagi T, Sato N, Hashino K, Maeno Y, Kazue T, Eto G, Yamakawa R. Long-term consequences of Kawasaki disease. A 10- to 21 year follow-up study of 594 patients. Circulation. 1996;94:1379-85. https:// doi.org/10.1161/01.CIR.87.5.1776.

3. Goh YG, Ong CC, Tan G, Liang CR, Soomar SM, Terence Lim CW, Quek SC, Teo LSL. Coronary manifestations of Kawasaki disease in computed tomography coronary angiography. J Cardiovasc Comput Tomogr. 2018; 12(4):275-80. https://doi.org/10.1016/j.jcct.2017.12.003.

4. Dietz SM, van Stijn D, Burgner D, Levin M, Kuipers IM, Hutten BA, Kuijpers TW. Dissecting Kawasaki disease: a state-of-the-art review. Eur J Pediatr. 2017;176(8):995-1009. https://doi.org/10.1007/s00431-017-2937-5.

5. Baddour LM, Wilson WR, Bayer AS, Fowler VG, Bolger AF, Levison ME, Ferrier P, Gerber MA, Tani LY, Gewitz MH, Tong DC, Steckelberg JM, Baltimore RS, et al. Infective endocarditis: diagnosis, antimicrobial therapy, and management of complications: a statement for healthcare professionals from the committee on rheumatic fever, endocarditis, and Kawasaki disease, council on cardiovascular disease in the young, and the councils on clinical cardiology, stroke, and cardiovascular surgery and anesthesia, American Heart Association: endorsed by the infectious diseases society of America. Circulation. 2005;111:e394-ee434. https://doi.org/10.1161/CIRCULATIONAHA 105.165564.

6. Yoshida M, Oana S, Masuda H, Ishiguro A, Kato H, Ito S, Kobayashi T, Abe J. Recurrence of fever after initial intravenous immunoglobulin treatment in children with Kawasaki disease. Clin Pediatr (Phila). 2018;57(2):189-92. https://doi.org/10.1177/0009922817694459.

7. Tacke CE, Burgner D, Kuipers IM, Kuijpers TW. Management of acute and refractory Kawasaki disease. Expert Rev Anti-Infect Ther. 2012;10:1203-15. https://doi.org/10.1586/eri.12.101.

8. Miura M, Ohki H, Yoshiba S, Ueda H, Sugaya A, Satoh M, Yamagishi H. Adverse effects of methylprednisolone pulse therapy in refractory Kawasaki disease. Arch Dis Child. 2005;90:1096-7. https://doi.org/10.1136/adc.2004.062299.

9. Furukawa T, Kishiro M, Akimoto K, Nagata S, Shimizu T, Yamashiro Y. Effects of steroid pulse therapy on immunoglobulin-resistant Kawasaki disease. Arch Dis Child. 2008:93:142-6. https://doi.org/10.1136/adc.2007.126144.

10. Miura M, Kohno K, Ohki H, Yoshiba S, Sugaya A, Satoh M. Effects of methylprednisolone pulse on cytokine levels in Kawasaki disease patients unresponsive to intravenous immunoglobulin. Eur J Pediatr. 2008;167:111923. https://doi.org/10.1007/s00431-007-0642-5.

11. Ogata S, Bando Y, Kimura S, Ando H, Nakahata Y, Ogihara Y, Kaneko T, Minoura K, Kaida M, Yokota Y, Furukawa S, Ishii M. The strategy of immuneglobulin resistant Kawasaki disease: a comparative study of additional immuneglobulin and steroid pulse therapy. J Cardiol. 2009;53:159. https://doi.org/10.1016/j.jjcc.2008.08.002

12. Teraguchi M, Ogino H, Yoshimura K, Taniuchi S, Kino M, Okazaki H, Kaneko K. Steroid pulse therapy for children with intravenous immunoglobulin therapy-resistant Kawasaki disease: a prospective study. Pediatr Cardiol. 2013;34:959-63. https://doi.org/10.1007/s00246-012-0589-9.

13. Ebato T, Ogata S, Ogihara Y, Fujimoto M, Kitagawa A, Takanashi M, Ishii M. The clinical utility and safety of a new strategy for the treatment of refractory Kawasaki disease. J Pediatr. 2017;191:140-4. https://doi.org/10. 1016/j.jpeds.2017.08.076

14. Burns JC, Best BM, Mejias A, Mahony L, Fixler DE, Jafri HS, Melish ME, Jackson MA, Asmar BI, Lang DJ, Connor JD, Capparelli EV, Keen ML, et al. Infliximab treatment of intravenous immunoglobulin-resistant Kawasaki disease. J Pediatr. 2008;153:833-8. https://doi.org/10.1016/j.jpeds.2008.06.011.

15. Youn Y, Kim J, Hong YM, Sohn S. Infliximab as the first retreatment in patients with Kawasaki disease resistant to initial intravenous 
immunoglobulin. Pediatr Infect Dis J. 2016;35:457-9. https://doi.org/10.1097/ INF.0000000000001039.

16. Tremoulet $A H$, Jain $S$, Jaggi $P$, Jimenez-Fernandez $S$, Pancheri JM, Sun $X$, Kanegaye JT, Kovalchin JP, Printz BF, Ramilo O, Burns JC. Infliximab for intensification of primary therapy for Kawasaki disease: a phase 3 randomised, double-blind, placebo-controlled trial. Lancet. 2014;383:1731-8. https://doi.org/10.1016/S0140-6736(13)62298-9.

17. Lopez-Olivo MA, Kakpovbia-Eshareturi V, des Bordes JK, Barbo A, Christensen $R$, Suarez-Almazor ME. Treating early undifferentiated arthritis: a systematic review and meta-analysis of direct and indirect trial evidence. Arthritis Care Res (Hoboken). 2018;70(9):1355-65. https://doi.org/10.1002/acr.23474.

18. Moher D, Liberati A, Tetzlaff J, Altman DG, PRISMA group. Preferred reporting items for systematic reviews and meta-analyses: the PRISMA statement. BMJ. 2009;339:b2535. https://doi.org/10.1016/j.jijsu.2010.02.007.

19. Chan $H$, Zhang $G$, Wang $M$, Yang $H$, Li Q. Infliximab versus methylprednisolone treatment for immunoglobulin resistant Kawasaki disease: a meta-analysis and adjusted indirect comparison. Prospero. 2016; CRD42016039693. Available at: http://www.crd.york.ac.uk/PROSPERO/ display_record.asp?!D=CRD42016039693.

20. Research Committee on Kawasaki Disease. Report of subcommittee on standardization of diagnostic criteria and reporting of coronary artery lesions in Kawasaki disease. Tokyo: Ministry of Health and Welfare; 1984.

21. Higgins JPT, Green S. Cochrane Handbook for systematic reviews of interventions. Version 5.1.0. The Cochrane collaboration. 2011. Available at: www.cochrane-handbook.org.

22. Slim K, Nini E, Forestier D, Kwiatkowski F, Panis Y, Chipponi J. Methodological index for non-randomized studies (minors): development and validation of a new instrument. J Surg. 2003;73:712-6. https://doi.org/ 10.1046/j.1445-2197.2003.02748.x

23. Stang A. Critical evaluation of the Newcastle-Ottawa scale for the assessment of the quality of nonrandomized studies in meta-analyses. Eur J Epidemiol. 2010;25:603-5. https://doi.org/10.1007/s10654-010-9491-z.

24. Guyatt GH, Oxman AD, Schünemann HJ, Tugwell P, Knottnerus A. GRADE guidelines: a new series of articles in the journal of clinical epidemiology. Clin Epidemiol. 2011;64:380-2. https://doi.org/10.1016/j.jclinepi.2010.09.011.

25. Stata Corp. Stata statistical software: release 14. StataCorp LP: College Station; 2013. Available at: http://www.stata.com/support/faqs/resources/ citing-software-documentation-fags/.

26. Brozek J, Oxman A, GRADEpro SH. Computer program. Version 3.6.1 for windows. 2011. Available at: http://tech.cochrane.org/revman/otherresources.

27. Son MB, Gauvreau K, Burns JC, Corinaldesi E, Tremoulet AH, Watson VE, Baker A, Fulton DR, Sundel RP, Newburger JW. Infliximab for intravenous immunoglobulin resistance in Kawasaki disease: a retrospective study. J Pediatr. 2011;158:644-649.e1. https://doi.org/10 1016/j.jpeds.2010.10.012.

28. Mori M, Hara T, Kikuchi M, Shimizu H, Miyamoto T, Iwashima S, Oonishi T, Hashimoto K, Kobayashi N, Waki K, Suzuki Y, Otsubo Y, Yamada H, Ishikawa C, Kato T, Fuse S. Infliximab versus intravenous immunoglobulin for refractory Kawasaki disease: a phase 3, randomized, open-label, activecontrolled, parallel-group, multicenter trial. Sci Rep. 2018;8(1):1994. https:// doi.org/10.1038/s41598-017-18387-7.

29. Newburger JW, Sleeper LA, McCrindle BW, Minich LL, Gersony W, Vetter VL, Atz AM, Li JS, Takahashi M, Baker AL, Colan SD, Mitchell PD, Klein GL, et al. Randomized trial of pulsed corticosteroid therapy for primary treatment of Kawasaki disease. N Engl J Med. 2007;356:663-75. https:/doi.org/10.1056/NEMMoa061235.

30. Sundel RP, Baker AL, Fulton DR, Newburger JW. Corticosteroids in the initial treatment of Kawasaki disease: report of a randomized trial. J Pediatr. 2003; 142:611-6. https://doi.org/10.1067/mpd.2003.191.

31. Kurokawa Y, Masuda H, Kobayashi T, Ono H, Kato H, Imadome Kl, Abe J, Abe $Y$, Ito $S$, Ishiguro A. Effective therapy with infliximab for clinically mild encephalitis/encephalopathy with a reversible splenial lesion in an infant with Kawasaki disease. Nihon Rinsho Meneki Gakkai Kaishi. 2017;40:190-5. https://doi.org/10.2177/jsci.40.190.

32. Xue LJ, Wu R, Du GL, Xu Y, Yuan KY, Feng ZC, Pan YL, Hu GY. Effect and safety of TNF inhibitors in immunoglobulin-resistant Kawasaki disease: a meta-analysis. Clin Rev Allergy Immunol. 2017;52:389-400. https://doi.org/10. 1007/s12016-016-8581-4.

33. Yang X, Liu G, Huang Y, Chen S, Du J, Jin H. A meta-analysis of re-treatment for intravenous immunoglobulin-resistant Kawasaki disease. Cardiol Young. 2015;25:1182-90. https://doi.org/10.1017/S1047951114002601.
34. Zhang L, Chen XP, Qin YH. Comment on a meta-analysis of re-treatment for intravenous immunoglobulin-resistant Kawasaki disease. Cardiol Young. 2016;26:1036. https://doi.org/10.1017/S1047951116000172.

35. Cbandelia S. A meta-analysis of retreatment for intravenous immunoglobulin resistant Kawasaki disease. Cardiol Young. 2015;26:1228. https://doi.org/10.1017/S1047951114002601.

36. Takahashi T, Sakakibara H, Morikawa Y, Miura M. Development of coronary artery lesions in indolent Kawasaki disease following initial spontaneous defervescence: a retrospective cohort study. Pediatr Rheumatol Online J. 2015;13:44. https://doi.org/10.1186/s12969-015-0042-8.

37. Tewelde H, Yoon J, Vanlttersum W, Worley S, Preminger T, Goldfarb J. The harada score in the US population of children with Kawasaki disease. Hosp Pediatr. 2014;4:233-8. https://doi.org/10.1542/hpeds.2014-0008.

38. Kil HR, Yu JW, Lee SC, Rhim JW, Lee KY. Changes in clinical and laboratory features of Kawasaki disease noted over time in Daejeon, Korea. Pediatr Rheumatol Online J. 2017;15:60. https://doi.org/10.1186/s12969-017-0192-y.

39. Nagakura A, Morikawa Y, Sakakibara H, Miura M. Bradycardia associated with prednisolone in children with severe Kawasaki disease. J Pediatr. 2017;185: 106-111.e1. https://doi.org/10.1016/j.jpeds.2017.02.074.

40. Millar K, Manlhiot C, Yeung RS, Somji Z, McCrindle BW. Corticosteroid administration for patients with coronary artery aneurysms after Kawasaki disease may be associated with impaired regression. Int J Cardiol. 2012;154: 9-13. https://doi.org/10.1016/j.jijcard.2010.08.070.

41. Kobayashi T, Saji T, Otani T, Takeuchi K, Nakamura T, Arakawa H, Kato T, Hara T, Hamaoka K, Ogawa S, Furuno K, Tokunaga H, Takatsuki S, et al. Efficacy of immunoglobulin plus prednisolone for prevention of coronary artery abnormalities in severe Kawasaki disease (RAISE study): a randomised, open-label, blinded-endpoints trial. Lancet. 2012;379:1613-20. https://doi.org/10.1016/S01406736(11)61930-2.

42. Ogata S, Ogihara Y, Honda T, Kon S, Akiyama K, Ishii M. Corticosteroid pulse combination therapy for refractory Kawasaki disease: a randomized trial. Pediatrics. 2012;129:e17-23. https://doi.org/10.1542/peds.2011-0148.

43. Song R, Yao W, Li X. Efficacy of four scoring systems in predicting intravenous immunoglobulin resistance in children with Kawasaki disease in a children's Hospital in Beijing, North China. J Pediatr. 2017;184:120-4. https://doi.org/10.1016/j.jpeds.2016.12.018.

44. Chen S, Dong Y, Yin Y, Krucoff MW. Intravenous immunoglobulin plus corticosteroid to prevent coronary artery abnormalities in Kawasaki disease: a meta-analysis. Heart. 2013;99:76-82. https://doi.org/10.1136/heartjnl-2012302126.

45. Chen S, Dong Y, Kiuchi MG, Wang J, Li R, Ling Z, Zhou T, Wang Z, Martinek M, Pürerfellner H, Liu S, Krucoff MW. Coronary artery complication in Kawasaki disease and the importance of early intervention: a systematic review and meta-analysis. JAMA Pediatr. 2016;170:1156-63. https://doi.org/ 10.1001/jamapediatrics.2016.2055

46. Hwang JY, Lee KY, Rhim JW, Youn YS, Oh JH, Han JW, Lee JS, Burgner D. Assessment of intravenous immunoglobulin nonresponders in Kawasaki disease. Arch Dis Child. 2011;96:1088-90. https://doi.org/10.1136/adc.2010. 184101.

47. Matsubara T, Furukawa S, Yabuta K. Serum levels of tumor necrosis factor, interleukin 2 receptor, and interferon-gamma in Kawasaki disease involved coronary-artery lesions. Clin Immunol Immunopathol. 1990;56:29-36. https:// doi.org/10.1016/0090-1229(90)90166-N.

48. Nakamura Y, Yashiro M, Uehara R, Sadakane A, Tsuboi S, Aoyama Y, Kotani K, Tsogzolbaatar EO, Yanagawa H. Epidemiologic features of Kawasaki disease in Japan: results of the 2009-2010 nationwide survey. J Epidemiol. 2012;22:216-21. https://doi.org/10.2188/jea.JE20110126.

49. Kim GB, Han JW, Park YW, Song MS, Hong YM, Cha SH, Kim DS, Park S. Epidemiologic features of Kawasaki disease in South Korea: data from nationwide survey, 2009-2011. Pediatr Infect Dis J. 2014;33:24-7. https://doi. org/10.1097/INF.0000000000000010.

50. Song F, Harvey I, Lilford R. Adjusted indirect comparison may be less biased than direct comparison for evaluating new pharmaceutical interventions. J Clin Epidemiol. 2008;61:455-63. https://doi.org/10.1016/j.jclinepi.2007.06.006.

51. Research Committee of the Japanese Society of Pediatric Cardiology; Cardiac Surgery Committee for Development of Guidelines for Medical Treatment of Acute Kawasaki Disease. Guidelines for medical treatment of acute Kawasaki disease: report of the research Committee of the Japanese Society of pediatric cardiology and cardiac surgery. Pediatr Int. 2014;56(2): 135-58. https://doi.org/10.1111/ped.12317. 